\title{
Ice-free cryopreservation by vitrification
}

\begin{abstract}
Ice-free vitrification of biospecimens is an alternative cryopreservation strategy to conventional preservation by freezing. Vitrification is the amorphous solidification of a supercooled liquid. This state is achievable by adjusting the cryoprotectant concentration and cooling rate to minimize nucleation and growth of ice crystals. The cooled liquid is then converted to a glassy state, notice. Without ice crystal formation, the biospecimens' extracellular matrix and cell viability is often better preserved. The decision to utilize an ice-free versus a freezing method for different types of biospecimens depends on which method is easiest for the product, whether the biospecimen will be washed before use, and whether an optimized method is already available. Generally, cells and tissues can be preserved using ice-free vitrification but isolated cells are easier to preserve using freezing methods because the cells are exposed to less risk of cryoprotectant-induced cytotoxicity and the cryoprotectant solutions are less viscous making the cells easier to handle. Samples such as tissue biopsies, Islets of Langerhans and encapsulated cells can also be preserved using either strategy, however the formation of ice during freezing may disrupt the tissues and distort or break capsules. Ice-free vitrification has major advantages for preservation of ovaries, heart valves, articular cartilage, and both natural and tissue engineered blood vessels, protecting the extracellular matrix and cells. In the extreme case of articular cartilage freezing results in less than $20 \%$ cell viability in contrast with $\geq 80 \%$ after ice-free vitrification.
\end{abstract}

Keywords: cryopreservation, vitrification, cells, tissues, tissue engineering, regenerative medicine, tissue banking

\author{
Volume I Issue 2 - 2014
}

\author{
Kelvin GM Brockbank, ,2,3 Zhenzhen Chen,' \\ Elizabeth D Greene,' Lia H Campbell' \\ 'Cell \& Tissue Systems Inc., USA \\ ${ }^{2}$ Institute for Bioengineering and Bioscience, Georgia Institute of \\ Technology, USA \\ ${ }^{3}$ Department of Regenerative Medicine and Cell Biology, \\ Medical University of South Carolina, USA
}

Correspondence: Kelvin GM Brockbank, Cell \& Tissue Systems Inc., 223I Technical Parkway, Suite A, North Charleston, South Carolina, USA, Tel 8437226756, Fax 8437226657, Email kbrockbank@celltissuesystems.com

Received: June 04, 2014 | Published: June 17, 2014

\section{Introduction}

Long-term preservation is crucial as an enabling technology for tissue banking for transplantation, regenerative medicine products that contain living cells and biopsy samples. Regenerative medicine reviews in particular have consistently highlighted the need for preservation methods for product development and commercialization. Strategic assessments of regenerative medicine have provided three critical priorities related to the need for better preservation methods: $:^{1,2}$

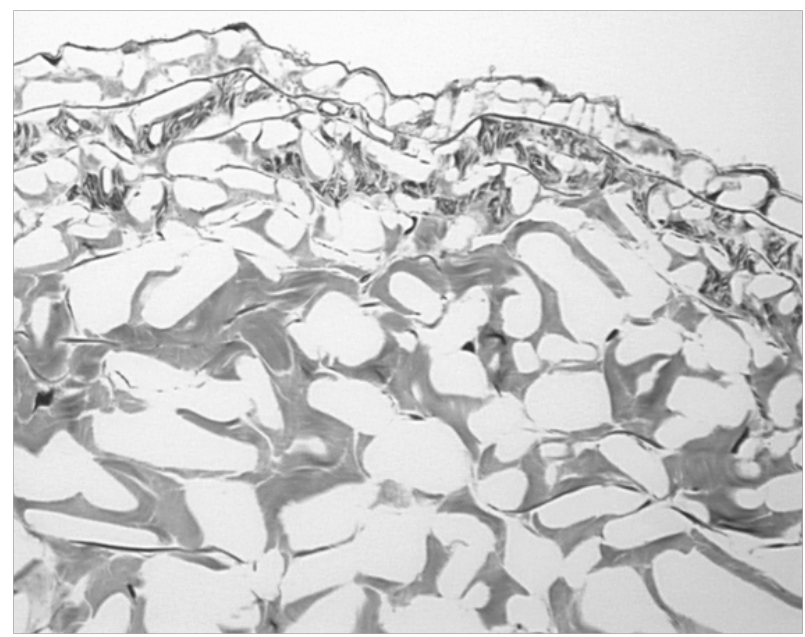

a)
- Assembling and Maintaining Complex Tissue

- Improving Tissue Preservation and Storage and

- Facilitating Effective Applications Development and Commercialization

Cryopreservation by freezing may maintain cell viability and adequate RNA, ${ }^{3}$ but histology and extracellular matrices are poorly preserved $^{4,5}$ due to ice formation within the tissues (Figure 1A).

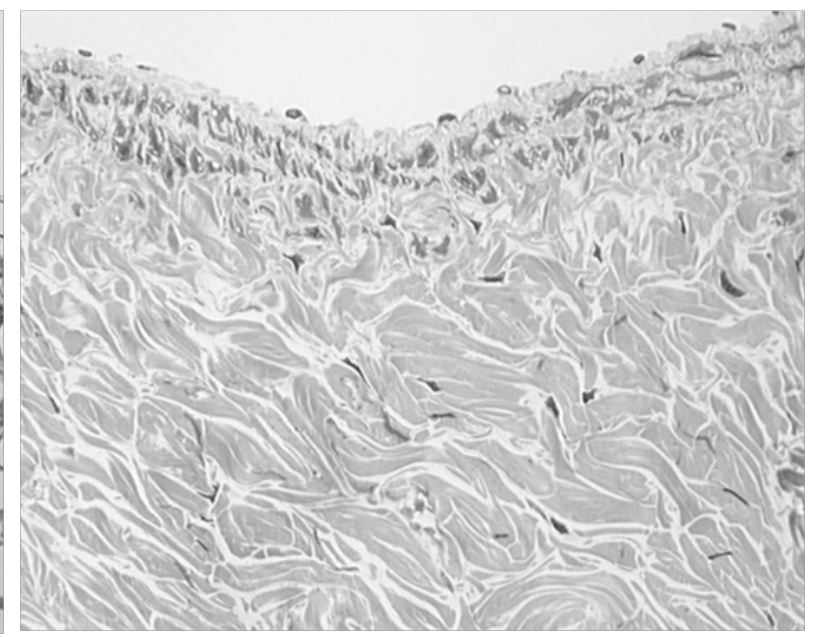

b)

Figure I Cryopreserved frozen (a) and vitrified (b) rabbit jugular veins demonstrating the relative presence of ice in frozen tissue, and absence of ice in vitrified tissue on the right after cryosubstitution at $-90^{\circ} \mathrm{C}$. The ice/water in the samples was cryosubstituted with methanol at $-90^{\circ} \mathrm{C}$ and fixed with $1 \%$ osmium tetroxide as it rewarmed so that the spaces occupied by ice (white spaces in tissue on (a)) were preserved. Araldite embedded tissue sections were stained with toluidine blue, original magnification $40 \mathrm{X}$. 


\section{Vitrification}

An alternative strategy for cryopreservation of biological materials is to promote vitrification by minimization of ice formation (Figure 1B). Vitrification was first proposed for cryobiology applications by Luyet. $^{6}$ Development of ice-free tissue cryopreservation by vitrification in our work was initially stimulated by the demonstration of large ice crystal domains within frozen tissues (Figure 1A). The methods employed for the avoidance of ice in tissues were based on the early work of Fahy et al., ${ }^{7}$ Rall \& Fahy, ${ }^{8}$ Rall. ${ }^{9}$ Vitrification is the amorphous solidification of a supercooled liquid. In ice-free cryopreservation the formation of ice is prevented by the presence of high concentrations of chemicals that interact strongly with water and, therefore, prevent water molecules from interacting to form ice. It has been shown that depressing the homogeneous nucleation temperature until it equals the glass-transition temperature permits vitrification of macroscopic biological systems. Prevention of freezing means that the water in a tissue remains liquid during cooling. As cooling proceeds, however, the molecular motions in the liquid permeating the tissue decrease. Eventually, an "arrested liquid" state known as a glass is achieved. It is this conversion of a liquid into a glass that is called vitrification (derived from vitri, the Greek word for glass). A glass is a liquid that is too cold or viscous to flow. A vitrified liquid is essentially a liquid in molecular stasis. Vitrification does not have any of the biologically damaging effects associated with freezing because no appreciable degradation occurs over time in living matter trapped within a vitreous matrix.

The protocol most commonly used for viable ice-free preservation by vitrification has been described in detail. ${ }^{10}$ Briefly, tissues in glass scintillation vials are gradually infiltrated with VS55 at $4{ }^{\circ} \mathrm{C}$ using cold cryoprotectant solutions in six sequential, $15 \mathrm{~min}$ steps of increasing cryoprotectant concentration. After addition of the final vitrification solution, the top of the vitrification solution is covered with $0.7 \mathrm{ml}$ of 2-methylbutane (isopentane, freezing point: $-160^{\circ} \mathrm{C}$, density: $0.62)$ at $4^{\circ} \mathrm{C}$ to prevent direct air contact. Samples are then cooled rapidly $\left(\sim 43^{\circ} \mathrm{C} / \mathrm{min}\right)$ to $-100^{\circ} \mathrm{C}$ by placing the sample in the precooled $\left(-135^{\circ} \mathrm{C}\right) 2$-methylbutane bath (fast cooling), followed by slow cooling $\left(3^{\circ} \mathrm{C} / \mathrm{min}\right)$ to $-135^{\circ} \mathrm{C}$ in air in the storage freezer, and then stored at $-135^{\circ} \mathrm{C}$ in either a mechanical storage freezer or $\geq 135^{\circ} \mathrm{C}$ near the top of vapor phase nitrogen freezer. Vitrified tissues are rewarmed in a two-stage process including slow warming $\left(30^{\circ} \mathrm{C} / \mathrm{min}\right)$ to $-100^{\circ} \mathrm{C}$ and then rapid warming $\left(225^{\circ} \mathrm{C} / \mathrm{min}\right)$ to $4^{\circ} \mathrm{C}$. After re- warming, the vitrification solution is removed in a stepwise manner at $4^{\circ} \mathrm{C}$ in seven sequential, $15 \mathrm{~min}$ steps. ${ }^{11}$

\section{Vitrification versus freezing}

Vitrification and freezing in cryopreservation are not mutually exclusive processes, the crystalline ice phase and vitreous phase often coexist within a system. Many cells in research and some cell therapy products, such as bone marrow, are simply cryopreserved after addition of cryoprotectants to cells in suspension in cryovials or bags by slow rate cooling, with or without induced nucleation, and storage at $-80^{\circ} \mathrm{C}$ or below $-135^{\circ} \mathrm{C}$. When cells are cryopreserved in suspension using such freezing methods the cells become vitrified in channels sandwiched between regions of ice. This occurs because during freezing the concentration of solutes in the unfrozen phase increases progressively until the point is reached when the residual solution is sufficiently concentrated to vitrify. Conventional freezing cryopreservation techniques are optimized by designing protocols that avoid intracellular freezing. The cell contents vitrify due to the combined processes of dehydration, cooling and the promotion of vitrification by cell permeating cryoprotectants and intracellular macromolecules. So technically, the cells are vitrified even though the method is a freezing method. In contrast when cells that survive freezing in suspension are placed on a substrate and cryopreserved using the same simple freezing methods often very low cell viability post-rewarming occurs (Figure 2). This is likely due to the cells being immobilized on a substrate so that they cannot move away from forming ice crystals. Further optimization of the freezing method is required to maximize cell viability and attachment. Similarly suspended chondrocytes are easy to cryopreserve using freezing strategies but not when embedded in their natural tissue matrices.

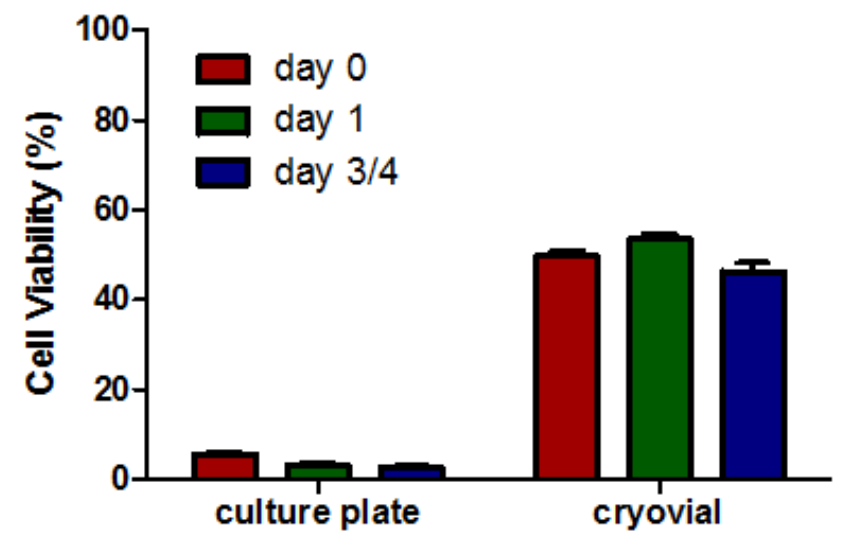

Figure 2 Cell viability after cryopreservation. Keratinocytes were cryopreserved suspended in vials or adhered on culture plates in 10\% DMSO in RPMI culture medium. Metabolic activity was measured immediately after thawing and for several days post thaw. Cell viability (\% untreated controls) was calculated as the mean $( \pm$ SEM) of 120 replicates.

Cell suspensions can be preserved by ice-free vitrification methods, but generally isolated cells are easier to preserve using freezing methods. This is because of cell exposure to high cryoprotectant concentrations under conditions that promote cryoprotectant-induced cytotoxicity during ice-free vitrification. Also the cryoprotectant formulations employed for ice-free vitrification are very viscous making it more difficult to handle cell suspensions during the cryoprotectant removal steps. Cytotoxicity can be minimized by using the least toxic cryoprotectant concentration possible that still promotes glass formation ${ }^{12,13}$ or by using addition and removal conditions that minimize exposure of biological materials to cytotoxic cryoprotectants. In the case of cells and tissues that are susceptible to cryoprotectant cytotoxicity the final steps in addition and first steps in removal of the cryoprotectants can be performed at sub-zero temperatures to minimize such concerns. Cryoprotectant cytotoxicity can be used to advantage in situations where cell viability is not required resulting in tissues that retain their extracellular matrix with significantly reduced immunogenicity. ${ }^{10,14-16}$

\section{Advantages of vitrification}

Ice-free vitrification offers several unique advantages over traditional slow rate freezing with cryoprotectants. This state is achievable by adjusting the cryoprotectant concentration and cooling rate to minimize nucleation and growth of ice crystals. The cooled liquid is then converted to a glassy state. Vitrification results in the elimination of ice crystal formation, both within the cells and their extracellular matrix and in the surrounding solution. ${ }^{17}$ Without ice crystal formation, the extracellular matrix and cell viability are better preserved. ${ }^{5,18}$ The protocols for vitrification are very simple. ${ }^{10}$ The concentration of cryoprotectants needed depends upon the sample size and material properties of the tissue associated with the cells. Small tissue samples, such as human embryos, may be placed directly into the cryoprotectant and then plunged directly into liquid nitrogen. Larger tissues need to be placed in increasing concentrations of cryoprotectant, in a step wise manner, in order to prevent cell damage due to osmotic effects. Higher concentrations of cryoprotectants may be required by tissue samples because the cooling rates achievable for larger samples are slower. Complete vitrification should eliminate 
concerns for the known damaging effects of intra- and extracellular crystallization that leads to loss of cell viability, tissue morphology, extracellular matrix integrity and RNA degradation.

\section{Applications}

Ice-free cryopreservation procedures have been developed and shown to provide effective preservation for a number of normal cell and tissue types, including monocytes, ova ${ }^{19}$ and early embryos, pancreatic islets, smooth muscle, blood vessels, heart valves and cartilage. ${ }^{11,20}$ The cell viability and functional survival of these vitrified materials is usually $80 \%$ or higher. Recent evidence indicates that icefree cryopreservation of embryos by vitrification is less traumatic than conventional slow freezing and is, therefore, a more effective means of cryopreserving the human embryo with excellent pregnancy outcomes for ice-free vitrified embryos. ${ }^{21}$ Support for using icefree vitrification to store cell and tissue therapy products and tissue biopsies can be obtained from published studies reporting retention of cell viability, phenotype and genotype employing 50-100 $\mu \mathrm{m}$ diameter tissue samples in capillary tubes ${ }^{22}$ and $250 \mu \mathrm{L}$ straws. ${ }^{23,24}$ The small sample methods utilized are not scalable for larger patient-derived tissue samples or engineered tissues because the methods employed by these investigators ${ }^{22-24}$ used $40 \%(\mathrm{v} / \mathrm{v})$ cryoprotective agent solutions. Such low concentration solutions require very rapid cooling/warming rates that are only possible with such very small sample volumes. Ice formation on warming is of comparable or greater importance than ice formation on cooling in determining survival of cryopreserved samples. The critical warming rates required for ice-free warming of vitrified aqueous solutions of glycerol, DMSO, ethylene glycol, polyethylene glycol 200 and sucrose are one to three orders of magnitude larger than critical cooling rates. ${ }^{25}$

Extensive studies of ice-free cryopreserved tissues have been performed over more than a decade and the ice-free vitrified tissues have been compared with conventionally, slow rate frozen and fresh control tissues. Slow rate freezing with $10-15 \%$ DMSO preserves at least some cell viability, whereas snap freezing with or without cryoprotectants or products like All protect Tissue Reagent (for DNA, RNA and protein preservation) and RNA later (for RNA stabilization) retain tissue RNA but usually not cell viability. Very rapid cooling techniques in which tissue samples are plunged into coolant in contact with metal plates can result in excellent ultrastructure preservation due to the absence of ice formation. The last method involves ice-free vitrification and was licensed for commercialization by Hitachi, the electron microscope manufacturer, based upon technology acquired from Life Cell Corporation. ${ }^{26}$ Thus the concept of vitrification strategies preserving cell/tissue structure and tissue matrix components is well established. Other investigators developed solutions and methods for rapid cooling of small samples of cells in narrow tubes, such as straws, but most mammalian tissues, for medical purposes, are too large for such containers requiring larger volumes of more concentrated cryoprotectants. The scale of these tissues also forces the use of slower cooling rates $\left(>40^{\circ} \mathrm{C} / \mathrm{min}\right)$ simply because more rapid cooling rates are not achievable. We have used a $55 \%(\mathrm{v} / \mathrm{v})$ solution, VS55, that consists of an $8.4 \mathrm{M}$ mixture of 1,2 propanediol, formamide, and DMSO in Euro Collins (EC) solution. ${ }^{8}$ The protocol is described in Khirabadi et al. ${ }^{27-29}$ US Patents.

We have successfully applied vitrification strategies to a variety of tissues tested to date from adult animals ${ }^{5,15,17,18,27-36}$ and some tissue engineered substitutes. ${ }^{37,38}$ Vitrification also results in superior retention of extracellular matrices compared with freezing methods ${ }^{5,18}$ and excellent post-transplant cell survival and tissue function in preserved grafts. ${ }^{30,32}$

Ice-free vitrification is outstanding for cryopreservation of articular cartilage. Freezing studies using a variety of animal articular cartilage models $\mathrm{s}^{39-42}$ and human cartilage biopsies ${ }^{43}$ have revealed no more than $20 \%$ chondrocyte viability following conventional freezing methods of cryopreservation employing low concentrations of either $\mathrm{ME}_{2} \mathrm{Se}$ with DMSO or glycerol as cryoprotectants. Chondrocytes in articular cartilage from larger mammals were not adequately preserved using the VS55 cryoprotectant formulation ${ }^{31}$ that was previously shown to be effective for relatively thin rabbit cartilage. ${ }^{42}$ Higher cryoprotectant concentrations were then employed for relatively thick porcine articular cartilage samples, without the bone attached, resulting in significantly improved cell viability. ${ }^{31}$ Increasing the cryoprotectant formulation to $83 \%$, VS83, using the same cryoprotectants while leaving the bone attached to the cartilage, resulted in $80.5 \%$ viability immediately after rewarming and viability returned to fresh control values by the second day of tissue culture under physiological conditions (Table 1). ${ }^{44}$ Johma et al. ${ }^{45}$ also demonstrated good viability when human knee articular cartilage with bone attached was treated with 4 different cryoprotective agents for mathematically determined periods of time at low temperatures. Cell viability, determined by several different assays, was $75.4 \pm 12.1 \%$.

Table I Ice-free cryopreservation of porcine cartilage -metabolic activity after rewarming

\begin{tabular}{lll}
\hline $\begin{array}{l}\text { Days of } \\
\text { culture }\end{array}$ & $\mathbf{5 5 \%}$ Cryoprotectants* & $\mathbf{8 3 \%}$ Cryoprotectants* \\
\hline 0 & $22.7 \pm 2.8$ & $80.5 \pm 6.8$ \\
1 & $21.6 \pm 1.6$ & $92.8 \pm 5.3$ \\
2 & $26.9 \pm 4.7$ & $101.6 \pm 6.7$ \\
3 & $28.4 \pm 5.4$ & $106.6 \pm 11.3$ \\
4 & $24.0 \pm 3.4$ & $112.8 \pm 13.4$ \\
7 & $26.2 \pm 1.0$ & $102.4 \pm 15.0$ \\
\hline
\end{tabular}

Full thickness cartilage plugs were preserved with bone attached and stored below $-135^{\circ} \mathrm{C}$. After rewarming the bone was removed and the cartilage plugs tested immediately and at frequent intervals over a week of tissue culture

*Results presented as the mean $\pm \mathrm{I}$ standard error, $\mathrm{n}=5$, all statistical comparisons between groups were significant at $p<0.05$. Data expressed in percent of untreated control values using the resazurin assay.

\section{Disadvantages}

We have observed solution fractures in ice-free vitrified samples stored in vapor phase nitrogen ${ }^{33}$ but only once seen a macroscopic tissue fracture in a specimen (Brockbank, unpublished observations). We believe this to be due to use of relatively slow cooling rates as the samples go through the glass transition phase change. However, we cannot rule out the possible presence of micro fractures being present in some tissues. Thermo-mechanical stress is the response of a material to volume changes associated with expansion or shrinkage of the material during cooling. Significant temperature gradients arise when a specimen of a significant size is cooled from outside in and become increasingly severe as the cooling rate increases resulting in a potential risk of sample cracking. When the level of stress exceeds the strength of the material, structural damage follows with fracture formation as its most dramatic outcome. ${ }^{46,47}$ Thermomechanical effects in cryopreservation have been extensively studied by Eisenberg et al. ${ }^{48}$

\section{Conclusion}

Ice-free cryopreservation strategies can be used for preservation of most cells and tissues. In some cases, particularly for cells, cryopreservation by freezing may be easier to perform. It is in natural and engineered tissue cryopreservation that ice-free methods excel often permitting significantly better preservation of cells, the extracellular matrix and tissue functions than freezing preservation methods. 


\section{Acknowledgements}

This work was supported in part by a US Public Health Grant from the National Institute of Biomedical Imaging and Bioengineering, Grant \# R43 EB014614, to KGMB. The content is solely the responsibility of the authors and does not necessarily represent the official views of the National Institute of Biomedical Imaging and Bioengineering or the National Institutes of Health. Commercial use of protocols disclosed in this work is subject to several issued US Patents $(6,194,137 ; 6,596,531 ; 6,740,484 ; 7,157,222 ; 8,440,390)$ and International Patents (available upon request).

\section{Conflict of interest}

Kelvin GM Brockbank is an owner and employee of Cell \& Tissue Systems. Lia H Campbell, Zhenzhen Chen, and Elizabeth D Greene are employees of Cell \& Tissue Systems.

\section{References}

1. http://tissueengineering.gov/welcome-s.htm

2. Johnson PC, Mikos AG, Fisher JP, et al. Strategic directions in tissue engineering. Tissue Eng. 2007;13(12):2827- 2837.

3. Votteler M, Layland SL, Lill G, et al. RNA isolation from fetal and adult human tissues for transcriptional profiling. Biotechnol J. 2013;8(3):338344.

4. Schenke-Layland K, Madershahian N, Riemann I, et al. Impact of cryopreservation on extracellular matrix structures of heart valve leaflets. Ann Thorac Surg. 2006;81(3):918-926.

5. Schenke-Layland K, Xie J, Heydarkhan-Hagvall S, et al. Optimized preservation of extracellular matrix in cardiac tissues: implications for long-term graft durability. Ann Thorac Surg. 2007;83(5):1641-1650.

6. Luyet BJ. The vitrification of organic colloids and of protoplasm. Bio dynamica. 1937;1(29):1-14.

7. Fahy GM, MacFarlane DR, Angell CA, et al. Vitrification as an approach to cryopreservation. Cryobiology. 1984;21(4):407-426.

8. Rall WF, Fahy GM. Ice-free cryopreservation of mouse embryos at -196 degrees C by vitrification. Nature. 1985;313(6003):573-575.

9. Rall WF. Factors affecting the survival of mouse embryos cryopreserved by vitrification. Cryobiology. 1987;24(5):387-402.

10. Brockbank KGM, Chen Z, Greene ED, et al. Vitrification of heart valve tissues. In: Walkers WF, Oldenhof $\mathrm{H}$, editors. Cryopreservation and freeze-drying protocols. Methods in Molecular Biology. USA: Springer; 2014.

11. Taylor MJ, Song YC, Brockbank KGM. Vitrification in tissue preservation: new developments. In: Lane N, Fuller BJ, Benson EE, editors. Life in the Frozen State. London: Taylor and Francis Books, CRC Press; 2004. p. 603-642.

12. Fahy GM, Levy DI, Ali SE. Some emerging principles underlying the physical properties biological actions and utility of vitrification solutions Cryobiology. 1987;24(3):196-213.

13. Fahy GM. Biological effects of vitrification and devitrification. In: Pegg DE, Karow AM, editors. The biophysics of organ preservation. USA: Plenum Publishing Corp; 1987. p. 265-297.

14. Lisy M, Pennecke J, Brockbank KG, et al. The performance of ice-free cryopreserved heart valve allografts in a orthotopic pulmonary sheep model. Biomaterials. 2010;31(20):5306-5311.

15. Brockbank KG, Schenke-Layland K, Greene ED, et al. Ice-free cryopreservation of heart valve allografts: better extracellular matrix preservation in vivo and preclinical results. Cell Tissue Bank. 2012;13(4):663-671.
16. http://www.google.co.in/patents/US8440390

17. Song YC, Khirabadi BS, Lightfoot F, et al. Vitreous cryopreservation maintains the function of vascular grafts. Nat Biotechnol. 2000;18(3):296299.

18. Brockbank KG, MacLellan WR, Xie J, et al. Quantitative second harmonic generation imaging of cartilage damage. Cell Tissue Bank. 2008;9(4):299-307.

19. Ting AY, Yeoman RR, Campos JR, et al. Morphological and functional preservation of pre-antral follicles after vitrification of macaque ovarian tissue in a closed system. Hum Reprod. 2013;28(5):1267-1279.

20. Brockbank KGM, Taylor MJ. Tissue Preservation. In: Baust JG, editor. Advances in Biopreservation. London: Taylor \& Francis Group, CRC Press; 2007. p. 157-196.

21. Balaban B, Urman B, Ata B, et al. A randomized controlled study of human Day 3 embryo cryopreservation by slow freezing or vitrification: vitrification is associated with higher survival metabolism and blastocyst formation. Hum Reprod. 2008;23(9):1976-1982.

22. Chong YK, Toh TB, Zaiden N, et al. Cryopreservation of neurospheres derived from human glioblastoma multiforme. Stem Cells. 2009;27(1):29-39.

23. Tan FC, Lee KH, Gouk SS, et al. Optimization of cryopreservation of stem cells cultured as neurospheres: comparison between vitrification slow-cooling and rapid cooling freezing protocols. Cryo Letters. $2007 ; 28(6): 445-460$

24. Kuleshova LL, Tan FC, Magalhaes R, et al. Effective cryopreservation of neural stem or progenitor cells without serum or proteins by vitrification. Cell Transplant. 2009;18(2):135-144.

25. Hopkins JB, Badeau R, Warkentin M, et al. Effect of common cryoprotectants on critical warming rates and ice formation in aqueous solutions. Cryobiology. 2012;65(3):169-178.

26. http://www.google.co.in/patents/US5336616

27. https://www.google.com/patents/US6194137

28. https://www.google.com/patents/US6740484

29. http://www.google.com.br/patents/US7157222

30. Song YC, An YH, Kang QK, et al. Vitreous preservation of articular cartilage grafts. J Invest Surg. 2004;17(2):65-70.

31. Brockbank KG, Chen ZZ, Song YC. Vitrification of porcine articular cartilage. Cryobiology. 2010;60(2):217-221.

32. Brockbank KGM, Song YC, Greene ED, MJ Taylor Quantitative analyses of vitrified autologous venous arterial bypass graft explants. Cell Preservation Technology. 2007;5(2):68-76.

33. Brockbank KG, Wright GJ, Yao H, et al. Allogeneic heart valve storage above the glass transition at $-80^{\circ}$ C. Ann Thorac Surg. 2011;91(6):18291835 .

34. Taylor MJ, Baicu S. Review of vitreous islet cryopreservation: Some practical issues and their resolution. Organogenesis. 2009;5(3):155-166.

35. Huber AJ, Aberle T, Schleicher M, et al. Characterization of a simplified ice-free cryopreservation method for heart valves. Cell Tissue Bank. 2012;14(2):195-203.

36. Huber AJ, Brockbank KG, Riemann I, et al. Preclinical evaluation of icefree cryopreserved arteries: structural integrity and hemocompatibility. Cells Tissues Organs. 2012;196(3):262-270.

37. Song YC, Chen ZZ, Mukherjee N, et al. Vitrification of tissue engineered pancreatic substitute. Transplant Proc. 2005;37(1):253-255.

38. Dahl SL, Chen Z, Solan AK, et al. Feasibility of vitrification as a storage method for tissue-engineered blood vessels. Tissue Eng. 2006;12(2):291-300 
39. Marco F, Leon C, Lopez-Oliva F, et al. Intact articular cartilage cryopreservation In vivo evaluation. Clin Orthop Relat Res. 1992;(283):11-20.

40. Ohlendorf C, Tomford WW, Mankin HJ. Chondrocyte survival in cryopreserved osteochondral articular cartilage. $J$ Orthop Res. 1996;14(3):413-416.

41. Wu FJ, Davisson TH, Pegg DE. Preservation of tissue-engineered articular cartilage. Cryobiology. 1998;37:410.

42. Song YC, Lightfoot FG, Chen Z, et al. Vitreous preservation of rabbit articular cartilage. Cell Preservation Technology. 2004;2(1):67-74.

43. Stone BB, Defranzo BE, Dicesare C. Cryopreservation of human articular cartilage for autologous chondrocyte transplantation. Cryobiology. 1998;(37):445-446.

44. Brockbank KGM, Chen Z. Successful Cryopreservation of Articular Cartilage Presented at the $36^{\text {th }}$ Annual Meeting of the American Association of Tissue Banks. Keystone; 2012.
45. Jomha NM, Elliott JA, Law GK, et al. Vitrification of intact human articular cartilage. Biomaterials. 2012;33(26):6061-6068.

46. Rabin Y, Taylor MJ, Walsh JR, et al. Cryomacroscopy of vitrification, Part I: A prototype and experimental observations on the cocktails VS55 and DP6. Cell Preserv Technol. 2005;3(3):169-183.

47. Steif PS, Palastro M, Wan CR, et al. Cryomacroscopy of vitrification Part II: Experimental observations and analysis of fracture formation in vitrified VS55 and DP6. Cell Preserv Technol. 2005;3(3):184-200.

48. Eisenberg DP, Taylor MJ, Rabin Y. Thermal expansion of the cryoprotectant cocktail DP6 combined with synthetic ice modulators in presence and absence of biological tissues. Cryobiology. 2012;65(2):117125 . 